\title{
PODA VERDE E PRODUÇÃO DO PESSEGUEIRO EM ALTA DENSIDADE
}

\author{
Ruy Inacio Neiva de Carvalho ${ }^{1}$, Giovambattista Sorrenti ${ }^{2}$, Stefanie Lais Kreutz Rosa ${ }^{1}$, Daniel William \\ Vendramin $^{1}$, Méllany Cunha Born Alves ${ }^{1}$, Claudinei Sperling ${ }^{1}$
}

\begin{abstract}
${ }^{1}$ Pontifícia Universidade Católica do Paraná, Escola de Ciências Agrárias e Medicina Veterinária, Agronomia, Rua Imaculada Conceição, 1155, Bairro Prado Velho, CEP: 80215-901Curitiba -PR, Brasil. Fone: 55413271 1534. E-mail: ruy.carvalho@pucpr.br; $\quad$ stefanie_lkr@hotmail.com; $\quad$ daniel.agro88@hotmail.com; $\quad$ mellanyborn@hotmail.com; claudinei_sperling@hotmail.com

${ }^{2}$ University of Bologna, Dep. of Agricultural Sciences, Viale G. Fanin 46, 40127 Bologna -Italia. Ph. +39 051 2096426, Fax +39 051 2096401. E-mail: g.sorrenti@unibo.it
\end{abstract}

\begin{abstract}
Resumo- O objetivo da pesquisa foi avaliar o efeito da poda verde sobre a quantidade $e$ qualidade de frutos do pessegueiro 'Chimarrita' cultivado em alta densidade. Os quatro tratamentos estudados foram: testemunha sem poda verde, uma poda verde realizada a 45 dias antes da colheita (AC), duas podas verdes a 45 e 75 dias AC e três podas verdes realizadas a 15, 45 e 75 dias AC. O método adotado para a poda verde foi a eliminação de ramos ladrões verticais e ramos voltados ao centro da copa e o desponte dos ramos acima de $2,3 \mathrm{~m}$ do solo oriundos das pernadas principais. Foram avaliados a massa total colhida, a massa média do fruto, os diâmetros do fruto, a acidez titulável, o grau Brix, o pH e a relação Brix/Acidez. Não houve influência das diferentes épocas de poda verde em relação à produção de frutos por planta, ao tamanho do fruto e à qualidade química dos pêssegos colhidos, com exceção do pH do suco que aumentou ao longo das três safras analisadas. Concluiu-se que a poda verde realizada de 15 a 75 dias antes da colheita não influenciou na produção e na qualidade de pêssegos produzidos em alta densidade.
\end{abstract}

Palavras-chave- Prunus pérsica. Pêssego. Brix. Acidez.

Abstract - The objective of the research was to evaluate the effect of summer pruning on quantity and quality of 'Chimarrita' peach cultivar trained in high density. The four treatments were: control without pruning, summer pruning at 45 days before harvest $(\mathrm{BH})$; two summer pruning at $\mathbf{4 5}$ and 75 days $\mathrm{BH}$; and three summer pruning performed at 15, 45 and 75 days $\mathrm{BH}$. The method used for pruning branches was the elimination of vertical branches facing the center of the canopy and the pruning of branches at $2.3 \mathrm{~m}$ above the ground originated of the main branches. The variables evaluated were the total mass harvested, the fruit weight, the fruit diameters, acidity, Brix, pH and ratio Brix/acidity. There was no influence of different summer pruning times on the fruits harvested per plant, fruit size and chemical quality of peaches harvested, except that the $\mathrm{pH}$ of the juice increased over the three years analyzed.
It was concluded that the green pruning of peach trees from 15 to 75 days before harvest not influence the yield and quality of peaches produced in high density.

Keywords - Prunus persica. Peach. Brix. Acidity.

Recebido em: 9 de novembro de 2015. Aprovado em: 10 de dezembro de 2015.

\section{INTRODUÇÃO}

O cultivo do pessegueiro [Prunus persica (L.) Batsch] está consolidado no Sul do Brasil, mas o detalhamento de técnicas de produção ainda é necessário em função das diferentes respostas das plantas quando submetidas a condições distintas de cultivo. O pessegueiro cv. Chimarrita é amplamente cultivado e apresenta boa adaptação nas diversas regiões de produção, em especial no Rio Grande do Sul (GALARÇA et al., 2013; NIENOW; FLOW, 2003) e no Paraná (ALVES et al., 2012).

A qualidade do fruto produzido é influenciada por diversas técnicas de cultivo como o porta-enxerto (GALARÇA et al., 2012; ROCHA et al., 2007), o sistemas de condução (GIACOBBO et al., 2003), a adubação (BRUNETTO et al., 2007; DOLINSKI et al., 2005) e o raleio (GOMES et al., 2005). Além destes, a poda verde é preconizada para assegurar a qualidade, em especial a coloração da epiderme do fruto, e a segurança dos produtos obtidos no sistema de produção integrada, pois ao favorecer o melhor arejamento da copa torna mais fácil os tratamentos fitossanitários (TIBOLA et al., 2007).

A poda do pessegueiro interfere no balanço energético da planta durante todo seu desenvolvimento, do início do ciclo de crescimento (primavera) até a instalação da endodormência (PEREIRA et al., 2012), interferindo na distribuição de reservas na planta, na alternância de produção e incidência de patógenos (RODRIGUES et al., 2008). Para racionalizar a condução do pomar e auxiliar na viabilização do agronegócio com esta fruteira, a operação de poda deve ser criteriosamente realizada, pois mobiliza vários funcionários e os gastos com mão-de-obra representam de 69,3 a 75,3\% do total do custo de produção de pêssegos no Paraná 
(PENTEADO JUNIOR; MAY DE MIO; RODIGHERI, 2009).

A poda verde consiste na eliminação de ramos do centro da copa e da base do tronco da planta e pode ser realizada em épocas e intensidades distintas, provocando respostas diferenciadas em função do vigor do genótipo avaliado. A poda verde aplicada em novembro, quatro semanas antes da colheita de pêssegos cv. Maciel, proporciona maior teor de sólidos solúveis totais e menor acidez nos frutos quando associada ao uso de plástico metalizado sob a copa (TREVISAN et al., 2006). Por outro lado, a poda verde do pessegueiro cv. Santa Áurea realizada a 40 dias antes da colheita não proporciona aumento no tamanho do fruto e no teor de sólidos solúveis totais (TREVISAN et al., 2008) e na cv. Flordaprince resultou em menor conteúdo de sólidos solúveis nos frutos (RODRIGUES et al., 2009). A diferença de resposta da planta à poda verde em função de condições distintas de cultivo justifica seu estudo em uma determinada situação regional, de forma a se identificar a eficiência de sua aplicação no sistema produtivo adotado.

O objetivo desta pesquisa foi avaliar o efeito da poda verde sobre a quantidade e qualidade de frutos do pessegueiro 'Chimarrita' cultivado em alta densidade.

\section{MATERIAIS E MÉTODOS/METODOLOGIA}

A pesquisa foi realizada com pessegueiros 'Chimarrita', enxertados sobre o porta-enxerto 'Okinawa' implantados em 2003 no espaçamento de $5 \mathrm{~m}$ entre fileiras e $1,5 \mathrm{~m}$ entre plantas na Fazenda Experimental Gralha Azul da PUCPR, no município de Fazenda Rio Grande, Paraná. Foram estudadas as safras de 2010, 2011 e 2012.

O pomar está sendo conduzido no sistema adensado em "Y" com plantas recebendo a poda de contenção da altura a $2,3 \mathrm{~m}$ do solo no início do outono. As podas verdes estudadas foram realizadas no período da brotação até a colheita dos frutos. O raleio de frutinhos foi realizado na segunda quinzena de setembro, deixando-se a distância de $10 \mathrm{~cm}$ entre os frutos em ramos mistos. Os tratamentos fitossanitários realizados foram aqueles adotados na rotina do pomar e recomendados para a produção integrada de pêssegos.

As plantas avaliadas receberam quatro diferentes épocas e intensidades de poda verde: testemunha sem poda verde, uma poda verde realizada a 45 dias antes da colheita, duas podas verdes a 45 e 75 dias antes da colheita e três podas verdes realizadas a 15,45 e 75 dias antes da colheita. $\mathrm{O}$ método adotado para a poda verde foi a eliminação de ramos ladrões com orientação vertical, ramos novos voltados ao centro da copa e o desponte dos ramos acima de 2,3 m do solo oriundos das pernadas principais. Os ramos podados foram levados a estufa de secagem a $62{ }^{\circ} \mathrm{C}$ por $42 \mathrm{~h}$ para determinação da massa seca em balança com precisão de $0,01 \mathrm{~g}$.
$\mathrm{Na}$ colheita, foi registrada a massa total de frutos colhida por planta e uma amostra aleatória e representativa de cinco frutos foi levada para o laboratório para execução das análises físicas de massa de fruto $(\mathrm{g})$ em balança de precisão de $0,01 \mathrm{~g} \mathrm{e}$ diâmetros meridional e equatorial sutural $(\mathrm{mm}) \mathrm{com}$ paquímetro manual com precisão de $0,1 \mathrm{~mm}$. Para a análise do $\mathrm{pH}$, foram separados em um becker $10 \mathrm{~g}$ da polpa e adicionados $90 \mathrm{~mL}$ de água deionizada. A mistura foi agitada para posterior leitura em pHmetro. As análises de sólidos solúveis totais foram realizadas com gotas do suco oriundos da polpa para observação em refratômetro portátil com precisão de $0,1^{\circ}$ Brix. Foram realizadas análises em duplicata em cada fruto. A acidez foi determinada por meio da titulação da mistura de $10 \mathrm{~g}$ da polpa mais $90 \mathrm{~mL}$ de água deionizado com $\mathrm{NaOH} 0,1 \mathrm{~N}$ até atingir o $\mathrm{pH}$ 8,1 .

O delineamento experimental adotado foi de blocos casualizados num esquema de parcelas subdivididas no tempo, formado pelos quatro tratamentos de poda verde na parcela principal e os três anos agrícolas na subparcela, com seis repetições. Cada parcela foi constituída por três plantas, sendo a planta central a avaliada, totalizando 72 plantas. Os dados foram submetidos à análise de variância e as médias com diferença pelo Teste $\mathrm{F}$ foram submetidas ao Teste Tukey $(\mathrm{p} \leq 0,05)$.

\section{RESULTADOS E DISCUSSÃO}

A massa seca acumulada de ramos retirados por pessegueiro ficou entre 266 e $649 \mathrm{~g}$ nos anos de 2010 e 2011, porém em 2012 ficou apenas entre 110 e 159 $\mathrm{g}$, indicando um ano de menor crescimento de ramos indesejáveis ao equilíbrio da planta (Tabela 1). A menor massa seca de ramos mal posicionados é favorável ao crescimento da árvore, pois não haverá desperdício de fotoassimilados em drenos que não contribuem para a produção de frutos. Este crescimento indesejável pode variar muito de um ano para o outro como detectado nos três anos estudados.

Tabela 1. Massa seca acumulada de ramos retirados com a poda verde de pessegueiro 'Chimarrita' em diferentes épocas em 2010, 2011 e 2012 em Fazenda Rio Grande, Paraná.

\begin{tabular}{lccc}
\hline \multicolumn{1}{c}{ Época de poda verde } & \multicolumn{3}{c}{$\begin{array}{c}\text { Massa seca de ramos podados } \\
\left(\mathrm{g} \cdot \mathrm{planta}^{-1}\right)\end{array}$} \\
\cline { 2 - 4 } (dias antes da colheita) & 2010 & 2011 & 2012 \\
\hline Sem poda & 0 & 0 & 0 \\
45 dias & 467 & 340 & 110 \\
45 e 75 dias & 266 & 398 & 159 \\
15, 45 e 75 dias & 388 & 649 & 131 \\
\hline
\end{tabular}

O ciclo médio da floração à colheita da cultivar Chimarrita é de 114 dias na região do experimento (ALVES et al., 2012). O início da poda verde desde 75 dias antes da colheita proporcionou a menor massa de ramos podados em 2010, o que é desejável. Já em 2011, este tratamento precoce não resultou na 
redução na massa de ramos mal localizados retirados da copa, identificando um ano com condições propícias ao crescimento vegetativo excessivo. Em 2012, com a copa mais equilibrada, a poda verde em diferentes épocas proporcionou a retirada mais regular de ramos da planta e com menor massa seca.

Segundo Galarça et al. (2013) foram retirados 361 $\mathrm{g}$ de ramos verdes com a poda da cultivar Chimarrita no Rio Grande do Sul e de acordo com Rocha et al. (2007), massa seca inferior a $80 \mathrm{~g}$ por planta foi retirada em Pelotas, RS, mesmo em porta-enxertos diversos. Estas quantidades menores de ramos mal localizados em relação aos pomares no Paraná demonstram o maior crescimento vegetativo da planta em regiões de latitude mais baixa, o que exige maior rigor na tomada de decisão de quando e em que frequência se deve fazer a poda verde.

A diferença de produção de ramos indesejáveis na copa em anos consecutivos e de acordo com a época de sua realização não resultou em diferença tanto de massa total de frutos colhidos por planta, que foi de 14,0 kg.planta ${ }^{-1}$, quanto de massa média do fruto produzido, que foi de 93,3 g (Tabela 2). Com base nos dados de massa colhida por planta, a produtividade média do pomar pode ser estimada em 18,7 t.ha ${ }^{-1}$, dados que estão dentro de valores registrados para a cultivar na região paranaense. Dolinski et al. (2005), pesquisando a mesma cultivar na Lapa, Paraná, encontraram produtividade de 11,7 a 23,2 t.ha ${ }^{-1}$. Giacobbo et al. (2003) registraram produtividade menor que $14 \mathrm{t}^{-h^{-1}}$ em diferentes sistemas de condução, porém Nienow e Floss (2003) citaram a produtividade de até 34,0 t.ha ${ }^{-1}$ da mesma cultivar em Passo Fundo, RS.

Tabela 2. Produção de pêssegos 'Chimarrita' após diferentes épocas de poda verde em 2010, 2011 e 2012 em Fazenda Rio Grande, Paraná.

\begin{tabular}{|c|c|c|c|c|c|c|}
\hline \multirow{2}{*}{$\begin{array}{l}\text { Época } \\
\text { de poda } \\
\text { verde } \\
\text { (dias } \\
\text { antes da } \\
\text { colheita) }\end{array}$} & \multicolumn{3}{|c|}{$\begin{array}{l}\text { Massa colhida } \\
\left(\text { kg.planta }{ }^{-1}\right)^{\text {ns }}\end{array}$} & \multicolumn{3}{|c|}{$\begin{array}{l}\text { Massa do fruto } \\
\left(\mathrm{g} . \text { fruto }^{-1}\right)^{\mathrm{ns}}\end{array}$} \\
\hline & 2010 & 2011 & 2012 & 2010 & 2011 & 2012 \\
\hline $\begin{array}{l}\text { Sem } \\
\text { poda }\end{array}$ & 15,7 & 9,9 & 16,3 & 84,8 & 103,6 & 103,7 \\
\hline 45 & 14,6 & 11,9 & 17,0 & 88,5 & 103,7 & 95,7 \\
\hline 45 e 75 & 16,3 & 9,1 & 12,6 & 81,2 & 97,5 & 91,8 \\
\hline $\begin{array}{l}15,45 \mathrm{e} \\
75\end{array}$ & 15,9 & 15,1 & 13,8 & 82,5 & 94,9 & 91,6 \\
\hline $\begin{array}{l}\mathrm{CV}_{\text {poda }} \\
(\%)\end{array}$ & & 47,2 & & & 11,8 & \\
\hline $\begin{array}{l}\mathrm{CV}_{\text {ano }} \\
(\%)\end{array}$ & & 48,0 & & & 15,5 & \\
\hline
\end{tabular}

A massa média de fruto obtida também está dentro do intervalo citado para a cultivar no Paraná (Tabela 2). Dolinski et al. (2005) obtiveram massa de 88 a 125 g.fruto $^{-1}$, sendo os valores mais elevados obtidos apenas com a aplicação de doses de 160 kg.ha ${ }^{-1}$ de nitrogênio. Alves et al. (2012) encontraram massa média de frutos da mesma cultivar entre 78 e $124,9 \mathrm{~g}$ na mesma região paranaense. Massa de frutos inferiores às registradas nesta pesquisa para a cultivar Chimarrita foram relatadas por Brunetto et al. (2007), entre 89,27 e 98,27 g, por Rocha et al. (2007), massa menor que $84,65 \mathrm{~g}$ e Galarça et al. (2012) que encontraram massa média de apenas $78,5 \mathrm{~g}$ em Bento Gonçalves, no Rio Grande do Sul. Já Nienow e Floss (2003), estudando três safras do pessegueiro Chimarita no Rio Grande do Sul, encontraram massa média de fruto superior, entre 107,3 e $117 \mathrm{~g}$. Estes dados salientam o potencial da cultivar que vem sendo alcançado em tradicionais regiões de cultivo da fruteira.

$\mathrm{O}$ diâmetro equatorial sutural $(\mathrm{mm})$ e o diâmetro meridional $(\mathrm{mm})$, também não diferiram significativamente da testemunha nos três anos de avaliação nas diferentes épocas de poda e não houve formação de frutos deformados (Tabela 3). Rodrigues et al. (2009), avaliando o comprimento e diâmetro de frutos em poda leve e poda de renovação 45 dias após a colheita, não observaram diferença na produção de frutos em função das podas realizadas. Gomes et al. (2005) consideraram a classificação do pêssego Chimarrita segundo o diâmetro da fruta em três categorias: tipo 1 - com diâmetro maior ou igual a 57 $\mathrm{mm}$; tipo 2 - de 47 a $57 \mathrm{~mm}$; e tipo 3 - de 44 a 47 $\mathrm{mm}$. Considerando-se o diâmetro equatorial, embora não tenha havido diferença significativa entre os tratamentos, em 2011 houve maior ocorrência de frutos do tipo 1. Já em 2010 a média do diâmetro obtida enquadrou a produção na categoria de frutos tipo 2. Frutos do tipo 1 podem alcançar melhores preços no momento da comercialização no atacado.

Tabela 3. Tamanho de pêssegos 'Chimarrita' produzidos após diferentes épocas de poda verde em 2010, 2011 e 2012 em Fazenda Rio Grande, Paraná.

\begin{tabular}{|c|c|c|c|c|c|c|}
\hline \multirow{2}{*}{$\begin{array}{l}\text { Época } \\
\text { de poda } \\
\text { verde } \\
\text { (dias } \\
\text { antes da } \\
\text { colheita) }\end{array}$} & \multicolumn{3}{|c|}{$\begin{array}{l}\text { Diâmetro equatorial } \\
\text { sutural }(\mathrm{mm})^{\mathrm{ns}}\end{array}$} & \multicolumn{3}{|c|}{$\begin{array}{l}\text { Diâmetro meridional } \\
\qquad(\mathrm{mm})^{\mathrm{ns}}\end{array}$} \\
\hline & 2010 & 2011 & 2012 & 2010 & 2011 & 2012 \\
\hline $\begin{array}{l}\text { Sem } \\
\text { poda }\end{array}$ & 54,6 & 57,5 & 59,0 & 58,7 & 61,0 & 62,4 \\
\hline 45 & 54,9 & 57,3 & 56,9 & 59,6 & 60,8 & 58,7 \\
\hline 45 e 75 & 53,8 & 57,0 & 56,9 & 59,3 & 59,3 & 61,5 \\
\hline $\begin{array}{l}15,45 \mathrm{e} \\
75\end{array}$ & 54,0 & 55,3 & 56,5 & 59,3 & 58,0 & 58,4 \\
\hline $\begin{array}{l}\mathrm{CV}_{\text {poda }} \\
(\%)\end{array}$ & \multicolumn{3}{|c|}{6,2} & \multicolumn{3}{|c|}{5,4} \\
\hline $\begin{array}{l}\mathrm{CV}_{\text {ano }} \\
(\%)\end{array}$ & \multicolumn{3}{|c|}{7,2} & \multicolumn{3}{|c|}{6,8} \\
\hline
\end{tabular}


função da adubação nitrogenada, na região da LapaPR. Revista Brasileira de Fruticultura, Jaboticabal, v.27, n.2, p.295-299, 2005.

GALARÇA, S.P. et al Produção e qualidade de frutos de pessegueiros 'Chimarrita' e 'Maciel' sobre diferentes porta-enxertos. Pesquisa Agropecuária Brasileira, Brasília, v.47, n.12, p.1731-1736, 2012.

GALARÇA, S.P. et al Crescimento e desenvolvimento de pessegueiros 'Chimarrita' e 'Maciel' sobre diferentes porta-enxertos e locais de cultivo. Ciência Rural, Santa Maria, v..43, n.2, p.219-224, 2013.

GIACOBBO, C.L. et al. Comportamento do pessegueiro (Prunus persica L. Batsch) cv. Chimarrita em diferentes sistemas de condução. Revista Brasileira de Fruticultura, Jaboticabal, v.25, n.2, p.242-244, 2003.

GOMES, F.R.C. et al. Influência do manejo do solo e da intensidade de raleio de frutas, no crescimento e qualidade de pêssegos, cvs. Cerrito e Chimarrita. Revista Brasileira de Fruticultura, Jaboticabal, v.27, n.1, p. 60-63, 2005.

NIENOW, A.A.; FLOW, L.G. Produção de pessegueiro e nectarina no planalto médio do Rio Grande do Sul em anos de inverno ameno. Ciência Rural, Santa Maria, v.33, n.2, p. 241-246, 2003.

PENTEADO JUNIOR, J.F.; MAY DE MIO, L.L.; RODIGHERI, H.R. Avaliação dos custos em pomares de pessegueiro conduzidos nos sistemas integrado e convencional, nos municípios de Araucária e Lapa, Paraná. Ciência Rural, Santa Maria, v.39, n.8, p.2521-2526, 2009.
PEREIRA, G.P. et al Dinâmica da dormência de gemas de pessegueiro, ameixeira e caquizeiro na Fazenda Rio Grande, PR. Revista Brasileira de Ciências Agrárias, Recife, v.7, suplemento, p.820$825,2012$.

ROCHA, M.S. et al. Comportamento agronômico inicial da cv. Chimarrita enxertada em cinco portaenxertos de pessegueiro. Revista Brasileira de Fruticultura, Jaboticabal, v.29, n.3, p.583-588, 2007.

RODRIGUES, A. et al. Intensidade de poda verde em pessegueiro para controle da ferrugem Tranzschelia discolor (Fuckel) Tranzschel e Litvinov. Revista Brasileira de Fruticultura, Jaboticabal, v.30, n.3, p. 634-638, 2008.

RODRIGUES, A. et al. Desenvolvimento do pessegueiro 'Flordaprince' sob duas intensidades de poda verde. Bragantia, Campinas, v.68, n.3, p.673679, 2009.

TIBOLA, C.S. et al. Análise da conformidade na adoção das normas de produção integrada de pêssego. Ciência Rural, Santa Maria, v.37, n.4, p.1149-1152, 2007.

TREVISAN, R. et al. Uso de poda verde, plásticos refletivos, antitranspirante e potássio na produção de pêssegos. Pesquisa Agropecuária Brasileira, Brasília, v.41, n.10, p. 1485-1490, 2006.

TREVISAN, R. et al. Influência do plástico branco, poda verde e amino quelant@-K na qualidade de pêssegos 'Santa Áurea'. Bragantia, Campinas, v.67, n.1, p. 243-247, 2008. 